\title{
Managing expectations? The opportunities and limitations of e-learning applications in Conflict Prevention and Peacebuilding Training
}

\begin{abstract}
In recent decades, governmental and non-governmental organisations have increased the number and scale of Conflict Prevention and Peace Building (CPPB) activities in conflict-affected countries. This development has also led to an increase in personnel in these organisations, posing challenges for staff training. In response, many organisations are looking at e-learning applications to provide cost-effective training at a broad geographical scale. Online courses and 'serious games' have in particular received interest in recent years. In this paper we discuss the opportunities and limitations of such applications for CPPB training. We argue that they face challenges in contributing to skills and knowledge development, but emphasize nevertheless that these challenges are similar to those faced by current classroom training initiatives. The potential of technology should not be exaggerated, yet digital applications can broaden the scope of participation and professionalization in CPPB activities to a wider range of (non-Western) actors.
\end{abstract}

Keywords: e-learning, serious games, conflict prevention, peace building, training, technology, ICT

\section{Introduction}

The international community has become increasingly involved in ending conflict and violence in crisis-affected countries. External actors provide humanitarian and development assistance to (post-)conflict countries, engage in the reform of state institutions, security sectors, and national armies, and accord assistance to civil society organisations to support service delivery and government accountability. These types of activities can be captured under the arguably broad term of Conflict Prevention and Peace Building (CPPB). Moreover, while the ability of external actors to harness peace has been questioned by policymakers (e.g. following the Iraq and Afghanistan crises) and academics (e.g. Richmond \& Franks, 2009), the CPPB field has continued to grow. This can be seen from the increasing number of United Nations (UN) peacekeeping missions, but also non-UN military operations (Bellamy \& Williams 2015) and UN political missions (Gowan 2015). Since the launch of its Common Security and Defence Policy (CSDP) in 2003, the EU has also increased the number and size of its missions and operations (di Mauro, Krotz \& Wright 2017). While estimates for the large variety of civil society actors present in conflict-prone societies are not available, they have surely increased as part of the trend towards larger international CPPB efforts after the Cold War and the development of a CPPB professional field (e.g. Autesserre 2014).

Together with this increased engagement in CPPB activities, the international community has also devoted attention to training to prepare staff for (often) foreign missions. Some state governments have established training institutes specifically for this aim, such as the German Center for International Peace Operations (ZIF) and the Swedish Folke Bernadotte Academy (FBA). The UN has developed pre-deployment training standards for police and military contingents, while also taking on the task of training civilian personnel (UN 2017). The EU has since the start of its foreign missions and operations set up the European Security and Defence College (ESDC) to pool training resources of member states, while European Commission initiatives such as Europe's New Training Initiative for Civilian Crisis Management or ENTRi ${ }^{1}$ bring together major training providers in Europe to develop and implement new courses. Non- 
state actors are also highly active in the field, both as for-profit and not-for-profit organisations. It is important to recognize however that with the large numbers of personnel involved in CPPB activities, there are differences in staff training across organisations and states, and methods, standards, and evaluations of training can vary considerably.

For most organisations, training has initially been conceptualized as face-to-face, offline training. Yet increasing staff numbers have raised concerns on the preparedness of CPPB actors. Indeed, a recent UN Training Needs Assessment Survey (UN 2013) found that $30 \%$ of police and almost $50 \%$ of civilian UN peacekeeping personnel had not received pre-deployment training, while a similar EU (2015) survey found that only 50\% of all civilian staff had followed a pre-deployment training during the past five years. As employers and training providers cannot keep up with the number of staff deployed, they have increasingly looked at e-learning (Khan 2015), or the use of digital applications to support learning activities. <PULLOUT>For most organisations, the turn towards e-learning is driven by a need to both reach larger audiences and reduce costs. $\leq$ PULLOUT $>$ This can raise questions, however, with regard to whether quality is assured. $\leqslant$ PU⿴囗十)

In this paper, we investigate recent e-learning applications in the CPPB field and assess their potential as effective training tools. We focus in particular on online courses and serious games as these two types of digital applications have currently attracted a lot of interest in the field, as demonstrated by new projects and initiatives. There are important differences between both types, however, which we address below.

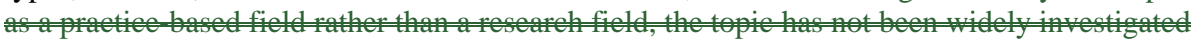

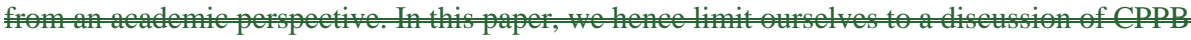
Ho of of

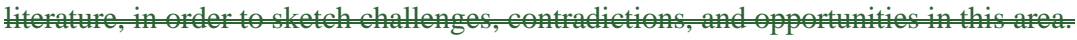

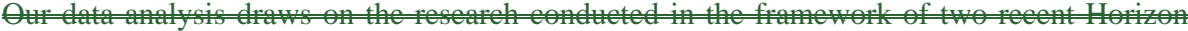

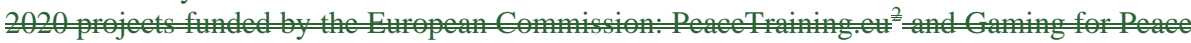
(GAP) ${ }^{3}$ Both proje ha for by andysing equse programmes and materials, by onduting over a 100 interviewith trainers, training developers, and training users (e.g. EU, UN, NGOs), by implementing an online survey targeted at these actors, and through the observation of classroem trainings organized by several major training institutes in Europe. Within the framework of both projects

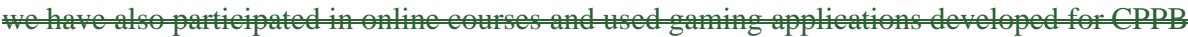
taining.TheGAP

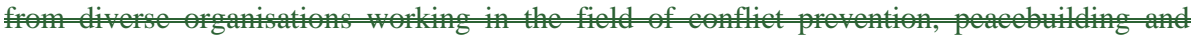

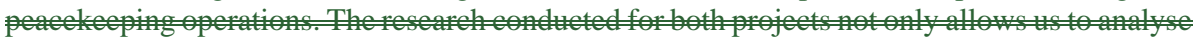
the opportmities and ehallenges with regard to e leaming in CPPB, butals howis relates to the field of CPPB training as steh, ineluding offline initiatives.

Our analyses indicate that e-learning applications do face challenges in terms of skills and knowledge development as well as learning evaluations, and that there is some scepticism in the field over their usefulness. Nevertheless, we argue that many of the critiques on e-learning in $\mathrm{CPPB}$ can also be voiced with regard to classroom training as they relate to a lack of consensus on what CPPB training is or should be. From this perspective, it is important to note that while e-learning applications can be improved, there is no immediate reason to reject them for being less effective than classroom training. If anything, e-learning opens the scope of training and offers opportunities to a new set of peacebuilders, increasingly from the developing world, to be part of the CPPB professional field. 
In the following section we first discuss the methodology used for the paper. Next, we consider what constitutes CPPB training and highlight different perceptions on this topic in the field. Next $\underline{\text { In Section } 3}$ we discuss recent e-learning applications in CPPB and analyse their constraints. Here, we first focus on online courses and then on recent serious game applications as both often have different goals and target audiences. We also evaluate these constraints against the broader challenges of the CPPB training field. We conclude by making a nuanced case for e-learning, but encourage further research on how to improve the quality and usefulness of specific applications.

\section{Methodology}

Furthermore, aAs CPPB training has mostly developed as a practice-based field rather than a research field, the topic has not been widely investigated from an acalemica scientific perspective. In this paper, we hence limit ourselves to a discussion of CPPB training by focusing on concrete examples and own insights rather than an established body of literature, in order to sketch challenges, contradictions, and opportunities in this area.

Our data analysis draws on the research conducted in the framework of two recent Horizon 2020 projects funded by the European Commission: PeaceTraining.e ${ }^{4}$ and Gaming for Peace (GAP)..$^{5}$ Both projects have focused on the current state of CPPB training in Europe and beyond by analysing course programmes and materials, by conducting over a 100 interviews with trainers, training developers, and training users (e.g. EU, UN, NGOs), by implementing an online survey targeted at these actors, and through the observation of several classroom trainings organized by developed a curriculum and serious game platform for personnel from diverse organisations working in the field of conflict prevention, peacebuilding and peacekeeping operations.

Within the framework of both projects, we have also-participated in online courses and used gaming applications developed for CPPB training in order to analyse their objectives, methods, and participant evaluation procedures. While the project has focused predominantly on European training institutes, including members of the ESDC and ENTRi, we have also turned our attention to initiatives outside the EU. Indeed, e-learning applications in the field of CPPB have been more strongly developed in the US by organizations such the Peace Operations Training Institute (POTI) and The United States Institute for Peace (USIP). The GAP project also developed a curriculum and serious game platform for personnel from diverse organisations working in the field of conflict prevention, peacebuilding and peacekeeping operations. The research conducted for both projects not only allows us to analyse the opportunities and challenges with regard to e-learning in CPPB, but also how this relates to the field of CPPB training as such, including offline initiatives.

Interviews conducted by the authors focused on e-learning experiences among users, developers, and trainers. We also draw on interviews from project partners with regard to this topic as well as the more general challenges facing CPPB training in Europe and elsewhere. Survey results with regard to e-learning experiences in CPPB were drawn from an online survey conducted by the PeaceTraining.eu project together with external partners. This survey was distributed through PeaceTraining.eu communication channels (website, newsletter, social media), the channels of individual project partners, as well as those of external partners. The survey ran between 14th of March 2018 and 30th of June 2018. 
In total 273 respondents completed the survey. Among these respondents $60 \%(\mathrm{~N}=164)$ had experience with e-learning and were asked additional questions related to this. These questions are used in our analysis. ${ }^{6}$

\section{What is CPPB training?}

Empirically, it is relatively easy to point to courses on Disarmament, Demobilization, and Reintegration (DDR), conflict analysis, Do No Harm etc. as 'CPPB training'. Conceptually, however, it is much more difficult to identify a unifying characteristic of what CPPB training is and/or should be. <PULLOUT>For some organisations, CPPB training mainly constitutes a briefing of the organisation (e.g. EU, UN), including its structures, working procedures, how to conduct report writing, specific country activities etc. 〈PULLOUT> This can be seen from pre-deployment training packages, for instance. This perspective is mainly driven by the practice of seconding/contracting experts within a certain domain (military, police, judiciary, administration) to perform tasks within the organisation and conflict setting. As such, CPPB practitioners are often not assumed to need additional capacity building.

For others, CPPB requires more fundamental training. These actors would point out the need for a deep knowledge of the local context in order not to implement faulty one-size-fits-all solutions, the need for continuous engagement with local actors to ensure local ownership, or for gendered conflict analyses to steer effective peacebuilding programmes. These perspectives are more widely shared in the academic field on peacebuilding (see for example Autesserre (2014) on the need for local versus domain-specific expertise). Yet they are increasingly also seen as part of good peacebuilding practice in international policy documents (OECD 2011). Moreover, as CPPB activities bring together a diverse range of actors with different national, institutional and personal backgrounds - including military officers and enlisted personnel from different services, agents of non-governmental organisations of varying scope and size, international civil servants, and individual "'citizen diplomats,",', (Rubinstein 2003: 29), - it has increasingly been recognized that specific training (e.g. intercultural communication skills) is needed to prepare staff to co-operate with others in a diverse professional environment.

Divergent learning objectives have implications for the type of training. A briefing of the organisation and working procedures mainly rests on factual knowledge and can be transmitted via lecture-based trainings. Tailored programme design, intercultural communication and negotiation skills, and gender mainstreaming arguably require more practice-based or experiential learning as they are focused on skills rather than knowledge. The predominant philosophy in the CPPB training field is that courses should be geared towards adult learning (Knowles 1984) and make use of participatory approaches and methods (Hmelo-Silver et al. 2013). This philosophy can for instance be derived from the websites and documents of the United Nations Institute for Training and Research (UNITAR), the ESDC, ENTRi, and the Kofi Annan International Peace Keeping Training Centre (KAIPTC) - all major training organisations or networks in the CPPB field.

Finally, tThe way training participants are evaluated is also dependent on learning content and the predominant view of what CPPB training should be. Training focusing on organisational knowledge and structures can introduce pre-and post-testing to determine whether knowledge was gathered, and potentially a longer-term post-test focusing on knowledge retention. For skills development, however, evaluation is more complex and a simulation exercise does not necessarily show how actors will behave in function. Furthermore, even if trainees are able to value and determine local needs and adapt programmes accordingly, they may not be empowered to do so because the mandate of the mission has already been decided at the political 
and/or donor level. This means that staff training on a local context does not necessarily guarantee that an organisation's CPPB activities will actually be tailored to that context. This aspect demonstrates how CPPB training and training evaluation are intrinsically connected with the complexity of CPPB itself.

\section{E-learning in CPPB: Navigating between technological scepticism and optimism}

E-learning can be broadly defined as 'the use of information and computer technologies to create learning experiences' (Horton 2006:1). As such, several approaches to e-learning exist. Here we discuss online courses and serious games. Serious games are games that serve an educational purpose rather than a recreational one. While they do not necessarily make use of digital technologies, many recent applications do, hence we discuss them as part of the broader domain of e-learning applications.

\section{Online courses in $\mathrm{CPPB}$}

Online courses can differ in both the technologies and methodologies used, the learning objectives, and the target audiences (Caplan \& Graham 2008). Traditional online courses are usually available to a limited audience of registered users and involve online materials in the form of texts, slides, infographics and videos. The learning method is usually linear but may also offer the opportunity to jump from one lesson to another. Some of the most traditional or first-generation e-learning forms include slide-sharing and limited texts. With the evolution of technology, videos, chat rooms, and other interactive materials have become more commonly used. A distinction can be made between synchronous and asynchronous online learning activities (Hrastinski 2008). Asynchronous learning activities occur when participants are not online at the same time while the reverse applies to synchronous learning.

Training institutions in the CPPB field use fully online courses or online modules to be taken as part of blended learning. For example, the ESDC has developed several online training modules or Autonomous Knowledge Units (AKUs). In addition, several online courses have been developed through the ENTRi project. UNITAR and the Peace Operations Training Institute (POTI) also offer a wide range of online courses on UN (peacekeeping) activities. Interestingly, POTI only offers distance learning modules and is specifically intended to reach peacekeepers and builders from developing countries. DCAF, the Geneva Centre for the Democratic Control of the Armed Forees, has also developed several online courses, in particular on Security Sector Reform. The United States Institute for Peace (USIP) offers a range of online courses, some of which have recently been made freely available to the general public.

Online courses can be supported by Learning Management Systems (LMS), which are webbased learning environments created for educational institutions and other organisations (e.g. companies) to provide online learning tools to (registered) platform users-Blackboard is among the most well-known (Piña 2013.) Users can access content including text documents (Word, pdf), audio-visual materials or online quizzes and surveys. An LMS can also foster communication and interaction between course users and providers and directly between course users with each other. Users can receive alerts when new content is uploaded and can often also contact providers directly with questions and upload assignments through the system. Communication between users is often stimulated by means of a course forum. LMS can be used in the framework of blended learning, which combines online with face-to-face/classroom learning, or for fully online courses. However, an LMS is not a requirement for setting up an 
online course. In this paper we do not analyse LMS as such, but rather their support to online courses.

Major training providers in the CPPB field make use of their own LMS. The ESDC hosts its courses on the ILIAS platform, UNITAR uses the learnatunitar.org platform. POTI also has its own online classroom platform. The United States Institute for Peace hosts the USIP Global Campus. The International Federation of Red Cross and Red Crescent Society also has a rich learning platform for the humanitarian sector.

\section{Critiques on Online Courses}

Most online courses in CPPB can be considered traditional online courses in which learning material is shared to users who can access it at different times (i.e. asynchronous format). The focus of these courses often lies on organisational structures and operational procedures (e.g. UN, EU) or key concepts such as security sector reform, protection of civilians, and mediation. Such courses are often entry-level courses and are created from the rationale that information that remains consistent over time can be put into an online format to save on costs. Development of an e-learning course is indeed dependent on the audience one expects to reach with the course, which should be large enough, but also whether the content is relatively robust to changes in the political, legislative, and operational landscape. For instance, while the ESDC is looking to turn (aspects of) pre-deployment training into an e-learning format, differences between mission objectives and procedures, and staff functions make the development of stable content particularly challenging (Rehrl \& Petteri 2015). If a course has to be tailored to very narrow audiences, it is likely to no longer be cost-effective.

The principal challenges with online courses in CPPB is that they tend to cause attention deficits or, to say it more straightforwardly, that they are 'boring'. <PULLOUT>Many online courses consist of the sharing of texts, slides, video or audio material (e.g. podcasts); learning becomes an individual experience and interaction is minimal.<PULLOUT $>$ Course user fora are rarely used by participants as a means for collaborative learning and experience sharing. For example, the POTI platform offers users the opportunity to post comments to a course and engage with each other, but comments are rarely posted and responses to others are even less frequent. In general, the use of new technologies (e.g. virtual class rooms) to promote participant interaction is largely absent from this field. This stands in contrast with the adult learning approaches advocated by CPPB training organisations.

Given their traditional format, there are also questions with regard to the level of learning online courses can achieve. As mentioned, many courses primarily relate information on EU or UN structures, key concepts etc. While critical notes can be made in the course text or via video's, podcasts etc. these courses do not always develop critical reflection on CPPB practices. Furthermore, it can be difficult to train and develop skills via such means. Online modules on intercultural communication or mediation can describe their importance and principles, but can hardly teach how (not) to do it. Assuming that an online course has contributed to skills development can hence be risky.

The knowledge-based content often contained in online courses also has implications for evaluation methods. The most common method is a multiple choice quiz for the user to test his or her knowledge. Many questions just require basic remembering of course text, however. Moreover, information can be copy-pasted or put up on a different screen. These features raise doubts on the value of certificates of completion, what has actually been learned, how long knowledge will be retained, and how it is used in practice. 
Given these features of many online courses in CPPB, it is not surprising that practitioners and trainers express scepticism over their quality. For example, a recent CPPB practitioner web survey $(\mathrm{N}=164)$ found that almost $80 \%$ of respondents agreed or strongly agreed with the statement "I learn better from in-person trainings than online programmes".' (PeaceTraining.eu D2.6, 2018 ). ${ }^{7}$ Perceptions of the values of e-learning among trainers and trainees are also rather negative: "If participants just want to gather knowledge, sure, $e$ learning is no problem. But the major advantage of in-person training is the networking and the interactivity, the discussions with participants and trainer, and between participants"-' (Trainer, December 2016). "I prefer residential training for interaction, because I learn a lot through experiential methods and using all senses, not just looking at a screen or hearing someone. Sitting in front of a PC, I don't have the same experience.".' (NGO Practitioner, February 2017). "-Online you cannot check whether people are even interested in what they are doing. In class, you can see it from their faces, if they are interested or asleep. You can put an evaluation form online but that is not the same. Ok, there are tools with which you can check how long people stayed on a page, otherwise people 'click click click' and get to the end and obtain a certificate "-'(Training Coordinator, February 2017). Clearly, the challenges described above are shared within the field.

\section{Comparison with Classroom Training}

Nonetheless, iIt is, however, als $\ominus$ important to qualify the above criticisms and take into account the intent and purpose of most online applications on the one hand, and how it compares to offline training on the other. Firstly, it is important to note that many online courses are explicitly advertised as introductory courses or modules, some of which can also be used in blended format learnings. From that viewpoint, online courses can actually improve current practice of sending training participants reading material beforehand which, given busy professional lives, they hardly do in practice. As such, they take over the knowledge component of training allowing for skills development through classroom activities. For example, participants can be made aware of the definition and theories of mediation via online learning and learn how to practice it via interactive role-plays in class.

Secondly, while new technologies can make online courses more interactive (e.g. virtual classrooms, video chat), there are also good reasons for course developers to keep to traditional formats. As internet availability is a common requirement, personnel already deployed in missions do not always have ready access to online platforms and materials. For practitioners from developing countries it can generally be more difficult to acquire the knowledge base necessary to function in the field given poor access to internet and prerequisite technologies. In order to ensure the availability of learning platforms for target groups with varying access to internet and technology, learning tools sometimes have to be adapted and simplified so that they depend on only minimal system requirements and connectivity. This can have implications for user-friendliness, design, and learning experiences. For instance, many POTI courses target developing country audiences and mainly focus on clear syllabi in downloadable pdf formats. Yet, they meet the core objective of the choice for e-learning which is to expand the scope of participants and make learning opportunities accessible at a larger scale. Indeed, the aforementioned CPPB practitioner web survey also found that $61 \%$ of respondents (strongly) agreed with the statement 'I prefer online learning because it allows me to study at my own time and on my own pace', while 67\% (strongly) agreed with the statement 'I prefer online learning because it is available at a low cost', demonstrating that issues of access continue to be individuals' main reason for choosing e-learning options. 
Thirdly, it is not necessarily certain that individuals learn better from offline than online training as such. Indeed, the number and scope of CPPB trainings is large and there is not necessarily a set benchmark or quality assurance. Even for organisations espousing adult learning principles, streams of long 'boring' lectures are sometimes lamented by trainers and practitioners. The ideal of interactive 'how to' skills development is not always attained by classroom courses (PeaceTraining.eu D3.5., 2017). Additionally, a certificate from an offline course does not necessarily mean more than that of an online course. Most certificates confirm attendance rather than a proof of obtaining the learning objectives because they experience difficulties in evaluating whether participants have actually learned. Post-tests can be introduced, but when this is the case, these often rely on a multiple-choice format similar to online courses. $<$ PULLOUT $>$ The problem of evaluation, whether participants have learned and whether they use it, is a shared challenge for online and offline training in CPPB. $<$ PULLOUT>

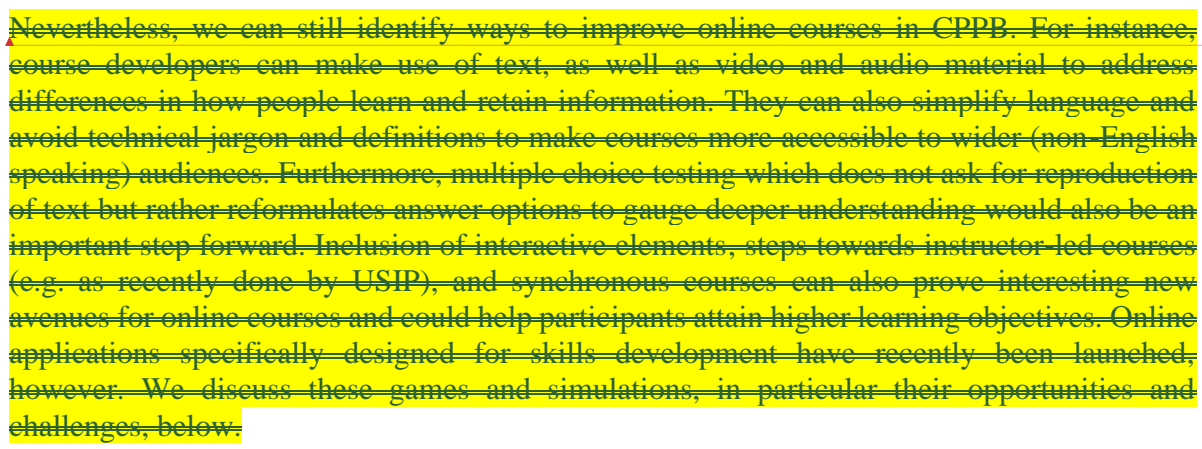

\section{Serious games in CPPB training}

Games and simulations are increasingly used learning applications in various fields, including peacebuilding (Brynen \& Milante 2012). This has also led to interest in the development of online games and virtual simulations for training. While games are often associated with entertainment and spare time activities, educators and trainers have looked at games as a tool to achieve particular learning objectives, and 'serious games' have been created for educational/training purposes (Kapp 2012; Ulicsak, \& Wright 2010). Contrary to what the concept suggests, serious games may still retain significant entertainment value or qualities which make them attractive and engaging for participants. This can actually increase learning. Different types of educational games exist and can serve different purposes. While games can transfer knowledge, they are can also be focused on skills development by placing players in virtual situations based on real-world scenarios allowing them to test and adapt behaviour based on responses to their actions. This 'learning by doing' method can aid participants in acquiring the skills needed to work in complex CPPB environments.

While there is still substantial debate and ongoing research on the advantages of gaming technologies for training (e.g. Boyle et al. 2016), games and virtual simulations have already made their way to the CPPB training field. An important difference exists between military and civilian training, however. For military training, games have been used for several decades already to prepare soldiers for battle on the ground. Yet not all games designed for military training are combat-related. For instance, the CultureShock Afghanistan game was designed to improve inter-cultural competences by placing players in the role of an Afghan village elder. The Cultural Awareness in Military Operations (CAMO) application has military personnel in 
training act out a scenario together (multi-player), but the experience of immersion is aided through means of a virtual environment of an Afghan village created in Second Life (PrasolovaFørland et al. 2013, see also Moenning et al. 2016)

Civilian applications are only starting to emerge, but an important example includes Mission Zhobia: Winning the Peace ${ }^{8}$, which brings players to a fictional country where the rule of law needs to be developed. DCAF also includes a simulation of security sector reform process in its 'Fundamentals of Strategic Advising in Reform Environments' course. ${ }^{9}$ Both applications are freely available online. The Gaming for Peace (GAP) project, funded by the European Commission's Horizon 2020 programme has also developed a game to train soft skills of CPPB staff, which is currently available online on their website. The gaming applications follow the same format in the sense that they are single player games in which the player is confronted with local and other actors in a dialogue with the principal aim of extracting relevant information needed to complete the task of the game. ${ }^{10}$ The player can choose between different responses which have optimal and sub-optimal outcomes.

The scenario is key to the development of a serious game. The goal is to introduce players to a realistic real-life situation (simulation) in which they can learn from their decision patterns. Nonetheless, the scenario is still a simplification of reality. For instance, Mission Zhobia gives the player the objective to implement a judicial sector reform plan. To do this successfully, the player needs to consult a variety of local actors to ensure the plan accommodates different needs. In order to extract information, the player also needs to build trust with interlocutors by showcasing background knowledge of the situation. While such soft skills indeed appear necessary in a particular work situation, reality is nonetheless simplified by restricting the amount of background information one needs to go through (as not to overburden the player) and the number of dialogue options. The game can be completed in one to three hours. The balance between reality and game is delicate and at the same time crucial for the learning experience. Dialogue options which are too obvious are not likely to work, for instance.

Games lend themselves in particular to skills development training, and do not necessarily focus on knowledge. Mission Zhobia and GAP both place the player in a fictional country context, but inspired on African and Middle Eastern settings respectively. The CAMO immersive simulation does train soldiers on particular cultural patterns and behaviours in Afghanistan and hence includes an important knowledge component. In general, feedback on these applications has been quite positive as shown through post-tests and interviews conducted by the developers (personal correspondences, October 2018). ${ }^{11}$ Nonetheless, as with many training applications in the CPPB field, it is not certain how much learning is retained and how much can/will be used in practice.

\section{Critiques on Serious Games}

With their focus on skills development, serious games in CPPB at first hand seem to hold more learning potential than many online courses. Nonetheless, it is important to take into account that both types of digital applications are fundamentally targeted at different audiences, which has implications for this assessment. While online courses increasingly aim to target developing country participants and expand the availability of introductory knowledge on CPPB structures and concepts, recent gaming applications appear to focus on Western target audiences who conduct or will conduct CPPB tasks in the global South.

Game developers' focus on Western CPPB practitioners can partly be explained by limitations on technological access and Internet availability in the Global South, but it comes with 
important challenges. For one, <PULLOUT> to a large extent, scenario development in recent serious games appears based on what Westerners think Westerners should do in particular contexts. $<$ PULLOUT $>$ While often backed up by research and local information, this issue can pose threats to the representation of local actors. A potential concern for some games concerns the conceptual understanding that Westerners have the task to build peace in the South, which can reproduce stereotypes of passive local populations. The GAP game puts the player in the position of European peacekeepers -which are by themselves increasingly rareand a Western identity appears implicit to the Mission Zhobia game.

While it would probably be a mistake to assume that the content of online courses is universal and not biased towards Western viewpoints, this is potentially a greater risk in the development of serious games which focus on behavioural patterns (e.g. Madni 2013). ${ }^{12}$ It is not certain that the behaviours accorded to non-Western actors in CPPB games are hence realistic from their own viewpoints. Moreover, it is also relatively uncertain whether the same game can be used to train other target audiences such as, for example, Pakistani peacekeepers going to the Democratic Republic of Congo. Although games can reach higher levels of learning than many current online courses in CPPB, their potential limitations in audience reach and scenario development do have to be taken into account and researched further.

\section{Comparison with Classroom Training}

Moreover, when assessing digital gaming applications, it is again important to make comparative reflections with regard to classroom training. Collaborative and experiential learning methods such as group work, role-playing and simulation are also used in classroom training and encouraged by many training institutes advocating adult learning principles. Here as well there is concern for Western bias, though. Training developers and trainers continue to be predominantly Western-based with Western participants and employers more likely to be able to pay course fees and enjoy training opportunities, and with many courses either taking place in the West or provided by Western trainers in the South.

These dynamics are not free from criticism by local actors and trainers, who often lament the flying in of expensive experts for short training courses and the neglect of local trainers. Indeed, the perspective that Westerners need to come and train on CPPB activities is also associated with the implicit view that local actors lack agency and expertise with regard to the conflict processes in their society. Furthermore, relatively little discussion has occurred on whether exercises developed from a Western knowledge base and mind-set actually work for developing country participants -in themselves not a homogenous group. While this is an issue already noted by Lederach in 1995, it is far from sure that the CPPB training field is implementing it in practice: 'My prevailing question is no longer: How do we adapt our conflict resolution model to a Hispanic context? Too often, I have discovered I am really asking. How do we fit Hispanics into our model? Rather my concern is this: How do we foster a pedagogical project that respects and empowers people to understand, participate in creating, and strengthen appropriate models for working at conflict in their own context?' (1995: 39).

\section{E-learning within the CPPB training field}

As discussed, different views exist on what CPPB training is or should be, how it should be done, and how it needs to be evaluated. Online courses fit predominantly with the view of CPPB 
training as a briefing of the organisational, legal and operational landscape. As such they focus on key information to transfer to CPPB practitioners in order to equip them for their function. Their employment is often based on a specific expertise already obtained, hence more in-depth training does not appear necessary. This view often prevails in international organisations. However, we also see courses on fundamental CPPB concepts (peacebuilding, mediation, security sector reform etc) and principles (gender inclusivity, local ownership), indicating that these aspects are increasingly regarded as standard knowledge for practitioners.

Most online courses focus on knowledge transfer and offer texts, slides, and audio or video material which can appear dull to users. Yet the same can be said of some classroom lectures which are the go-to method for offline knowledge development. Moreover, the traditional format followed by online CPPB courses can be explained by taking into account their target audiences. Major training providers such as POTI and UNITAR primarily attract course participants from developing countries (POTI 2018; UNITAR 2018) for which new technologies are difficult to access. By offering basic courses to a wide range of actors, it would appear that e-learning reaches its goal of opening learning opportunities to wider audiences. $\underline{\underline{I t}}$ remains to be investigated how this knowledge is used by participants and how it affects their professional development, however. Sceptics could argue that it is nothing more than certificate collection. Yet this also begs the question of how these certificates are actually regarded by employers in local settings. A more optimistic viewpoint could be that the knowledge gained from these basic online courses empowers developing country practitioners by acquainting them with the knowledge and discourse of the international peacebuilding community. These questions all warrant further research.

It) professionaldevelopment, hower. Seepties euldarge that it is nothing more than eeftifieate eollection. Yet this also begs the question of how these entifieates are actully regarded by

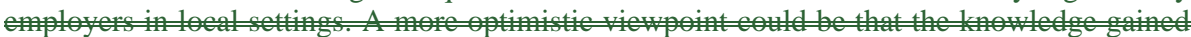

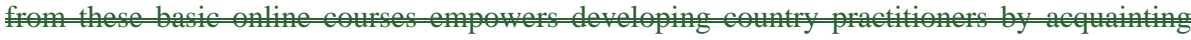
them with the knowledge and discourse of the international peacebuilding community. These questions all warrant further research.

Serious games fit more within the second view of CPPB training which calls for specific skills development to work effectively in new contexts. Such skills typically include inter-cultural communication, trust-building, conflict analysis etc. As such, they show more ambition in learning content or scenario development and objectives. These learning methods also fit more with the called for experiential learning by many training organisations. In terms of evaluation they rely on programmed feedback or, in some cases, instructor-based feedback as would be the case in a real-life training scenario. Serious games hence appear to be more advanced than traditional online courses with regard to learning objectives, method and evaluation.

Serious games also face risks, however, which are more strongly related to the second view of CPPB training as such. This includes whether the content or scenarios are Western-biased and whether the method itself works across different cultures. The complexity of these learning applications hence raises doubts over their ability to train on the right type of skillset as well as their generalizability. Indeed, while serious games are more ambitious than many online courses, their transformative potential for CPPB training may actually be less if their content and method are too restricted to Western audiences. Yet, thisThis holds true for games and simulations in classroom training as well, where perspectives from diverse actors can have unintended consequences for the flow of the exercise. The broader questions which require further research here would focus precisely on whether experiential and action-based learning methods work across different cultural (and other) backgrounds or whether they are 
fundamentally restricted to the a particular (Western) audience. Especially considering developing costs, these issues are important to address.

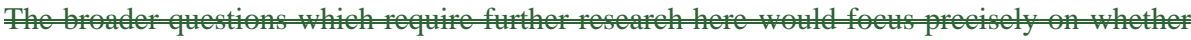

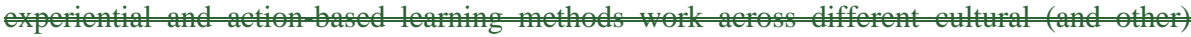
bakgounds or whether they are fundamentally restried to the a patieular (Western) audience. Especially considering developing costs, these issues are important to address.

\section{Conclusion}

In this paper we have analysed online courses and serious games as part of the recent turn towards the development and use of e-learning applications in the CPPB training field. <PULLOUT> In general, we argued that e-learning applications in CPPB face important constraints but that these limitations are often shared with classroom training initiatives. $<$ PULLOUT > Furthermore, e-learning, in particular in the form of online courses, does fulfil the aim of larger reach at lower costs, which is often its principal objective for developers as well as users. This reach increasingly includes developing country practitioners.

Given that current constraints of CPPB e-learning are shared with offline training, it is useful to reflect further on these challenges here and provide recommendations to address them. The most fundamental current challenge to CPPB training in general is arguably a lack of consensus on what staff should actually be trained on. Training in the field of CPPB has largely evolved from practice, responding to upcoming, topical needs. Some trainings focus on organisational structures and procedures, others focus on skills development (e.g. gender-sensitive programming), and some combine elements of both. All these types of trainings have merit, as long as they fit the profile of the staff function of an organisation, and hence respond to the concrete needs of the organisation's personnel. Nevertheless, human resource policies should be aware of the limits and merits of each type of training, whether online or offline. It can be sufficient for a training to focus primarily on basic organisational or conceptual knowledge as long as staff are not expected to apply that knowledge in practice (e.g. mediation techniques). For skills development training, trainings that offer some type of experiential learning are more suitable. There is thus a need to tailor trainings to expectations, both for online and offline training. Systematic evaluation of whether training fulfils these expectations is needed for both types.

A second challenge relates to the fact that current CPPB training contents and methods are primarily developed by Western actors, while developing country actors are actually becoming more prominent in CPPB activities. Given that training is intended to improve the knowledge and skills necessary to successfully engage in CPPB activities, it can only be beneficial to expand the training toolbox with experiences from a broader range of actors. This implies that training development, provision, and funding schemes need to be carefully revisited. Indeed, CPPB trainings increasingly have to cater to diverse target audiences working in diverse settings. $\leq$ PULLOUT > Developing online and offline training tools that cater to these diverse needs, can only be co-created by multicultural training development teams. $\langle$ PULLOUT $>$

There is, however, also room to improve e-learning applications themselves. Online courses in CPPB could be improved in different ways.

Nevertheless, we can still identify ways to improve online courses in CPPB.For instance, course developers can make use of text, as well as video and audio material to address differences in how people learn and retain information. They can also simplify language and avoid technical jargon and definitions to make courses more accessible to wider (non-English

heeft opmaak toegepast: Lettertype: Vet

heeft opmaak toegepast: Lettertype: Vet 
speaking) audiences. Furthermore, multiple choice testing which does not ask for reproduction of text but rather reformulates answer options to gauge deeper understanding would also be an important step forward. Inclusion of interactive elements, steps towards instructor-led courses (e.g. as recently done by USIP), and synchronous courses can also prove interesting new avenues for online courses and could help participants attain higher learning objectives. Online applications specifically designed for skills development have recently been launched, however. We discuss these games and simulations, in particular their opportmnities and ehallenges, below. While serious games are relatively new, recommendations for their development include a careful balance between simplification and realism, sufficient (in-game) feedback on participant behaviour, and technological accessibility.

Finally, more attention should be directed to technological access in general. 〈PULLOUT> The major benefit of e-learning is expanding the scope of training opportunities, which can only be supported if low-cost ICT are used and offered to participants. 〈PULLOUT> This means more priority should be given to widely used technologies including smartphone applications as a means to offer CPBB training. Expanding internet reach and lowering access costs, in particular in (post-conflict) developing countries, also contributes to strengthening CPPB training worldwide.

\section{References}

Autesserre, S. 2014, Peaceland: Conflict Resolution and the Everyday Politics of International Intervention, New York: Cambridge University Press.

Bellamy, A.J. \& Williams, P.D. 2015, 'Trends in Peace Operations, 1947-2013' in Koops, J. et al. eds, The Oxford Handbook of United Nations Peacekeeping Operations, Oxford: Oxford University Press: 13-42.

Boyle, E., et al. 2016, 'An update to the systematic literature review of empirical evidence of the impacts and outcomes of computer games and serious games' in Computers \& Education 94: 178-192.

Brynen, R. \& Milante, G. 2012, 'Peacebuilding With Games and Simulations' in Simulation \& Gaming 44:1: 27-35.

Caplan, D \& Graham, R. 2008. 'The Development of Online Courses' in Anderson, T. ed., Theory and Practice of Online Learning, Athabasca University, online book $2^{\text {nd }}$ edition: 245263.

di Mauro, D. Krotz, U., \& Wright, K. 2017, 'EU's global engagement: a database of CSDP military operations and civilian missions worldwide', Codebook: version 2.0. 2003-2017.

EU 2015. Civilian Planning and Conduct Capability Survey 2015. Unpublished.

Gowan, R. 2015, '10 Trends in Peace Operations', accessed on 12 April 2018 via http://peaceoperationsreview.org/thematic-essays/10-trends-in-peace-operations/

Hmelo-Silver, C.E. et al. 2013 eds., The International Handbook of Collaborative Learning, New York: Routledge.

Horton, W. 2006, E-Learning By Design, San Francisco: Pfeiffer. 
Hrastinski, S. 2008, 'Asynchronous and synchronous e-learning' in Educause Quarterly 31:4: 51-55.

Kapp, K.M. 2012, The Gamification of Learning and Instruction: Game-based Methods and Strategies for Training and Education, Pfeiffer and Company Publishers.

Khan, B.H. 2015, 'Introduction to E-Learning' in Khan, B.H. \& Ally, M. eds, International Handbook of E-Learning, Volume 1: Theoretical Perspectives and Research, New York: Routledge: 1-40.

Knowles, M. 1984, The Adult Learner, Gulf Publishing Company.

Lederach, J.P. 1995, Preparing for Peace: Conflict Transformation Across Cultures, New York: Syracuse University Press.

Madni, A.M. 2013, ‘Game-Based Simulation for Cross-Cultural Decision Making Training' in Human Factors and Ergonomics in Manufacturing \& Service Industries 23:2: 85-94.

Moenning, A., et al. 2016, 'Developing avatars to improve cultural competence in US soldiers' in 2016 IEEE Systems and Information Engineering Design Symposium: 148-152.

OECD 2011, International Engagement in Fragile States: Can't we do better?, Conflict and Fragility, OECD Publishing.

PeaceTraining.eu 2017, D3.5.: Integrated assessment report, public deliverable. Accessed $30^{\text {th }}$ of April 2019 via https://project.peacetraining.eu/project-structure/

PeaceTraining.eu 2018, D2.6.: Expert Feedback and Validation Report, non-public deliverable. www.project.peacetraining.eu

Prasolova-Førland, E., et al. 2013, 'Training Cultural Awareness in Military Operations in a Virtual Afghan Village: A Methodology for Scenario Development', 46th Hawaii International Conference on System Sciences (HICSS), Wailea, HI, USA, 7-10 January 2013.

Piña, A.A. 2013, 'Learning Management Systems: A Look at the Big Picture' in Kats, Y. ed., Learning Management Systems and Instructional Design: Best Practices in Online Education, Hershey: IGI Global: 1-19.

POTI 2018, '2017 Annual Report', accessed 13 October 2018 via https://d1quhl37gh6ot5.cloudfront.net/pdf/annual-report.pdf

Rehrl, J. \& Petteri, T. 2015 'Pre-Deployment Elearning For CSDP Missions/Operations' in eLearning \& Software for Education 1: 483-486.

Richmond, O.P. and Franks, J. 2009, Liberal Peace Transitions: Between State-building and Peacebuilding, Edinburgh: Edinburgh University Press.

Rubinstein, R.A. 2003 'Cross-Cultural Considerations in Complex Peace Operations' in Negotiation Journal 19:1: 29-49.

Sou, G. 2018, 'Trivial pursuits? Serious (video) games and the media representation of refugees', in Third World Quarterly 39:3: 510-526

Ulicsak, M. \& Wright, M. 2010, 'Games in Education: Serious Games. A FutureLab Literature \begin{tabular}{lllll} 
Review', & accessed & 13 & October & 2018 \\
\hline
\end{tabular} https://www.nfer.ac.uk/publications/FUTL60/FUTL60.pdf 
UN 2013, 'Global Peacekeeping Training Needs Assessment, Final Report - 2012-2013', accessed on 12 April 2018 via http://research.un.org/en/peacekeeping-community/Training

UN 2017, 'DPKO-DFS Core Pre-deployment Training Materials (CPTM 2017) for United Nations Peacekeeping Operations', accessed October 2013 via https://research.un.org/revisedcptm2017

UNITAR 2018，'2017 Results Report', accessed 13 October 2018 via http://www.unitar.org/sites/default/files/uploads/results_report_digital-compressed.pdf

Endnotes

${ }^{1}$ http://www.entriforccm.eu/

${ }^{z}$-www.peacetraining.eu

${ }^{3}$ https://gap-project.eut

${ }^{4}$ www.peacetraining.eu

${ }^{5}$ https://gap-project.eu/

${ }^{6}$ External partners for survey development and implementation were the European Peacebuilding Liaison Office (EPLO), the Global Partnership for the Prevention of Armed Conflict (GPPAC), and the Peace and Collaborative Development Network (PCDN). The survey made use of the Qualtrics software package. The Qualtrics setting only allowed 1 response per IP address to prevent single respondents to retake the survey multiple times.

${ }^{7}$ The survey was developed by PeaceTraining.eu together with external partners: European Peacebuilding Liaison Office (EPLO), Global Partnership for the Prevention of Armed Conflict (GPPAC), Peace and Collaborative Development Network (PCDN). The survey made use of the Qualtrics software package. Distribution of the survey was done via an anonymous link which was spread through PeaceTraining eu communication channels (newsletter, social media), a link from the PeaceTraining.eu web platform, the channels of individual consortium partners, as well as those of the external partners. The survey ran between 14th of March 2018 and 30 th of June 2018. The Qualtries setting only allowed 1 response per IP address to prevent single respondents to retake the survey multiple times. In total 273 respondents completed the survey. Among these respondents $60 \%(\mathrm{~N}=164)$ had experience with e-learning and were asked additional questions related to this.

${ }^{8}$ www.missionzhobia.org

${ }^{9}$ Issat.dcaf.ch

${ }^{10}$ This is a common feature of role-playing games in general

${ }^{11}$ The developers of GAP, Mission Zhobia, and CAMO presented their applications and findings on the PeaceTraining.eu final conference in October 2018. See: www.peacetraining.eu/conference/

${ }^{12}$ Nevertheless, Sou (2018) argues that serious games can provide more complex representations than those communicated by traditional media. He focuses in particular on serious games focusing on refugees. 